\title{
A computational procedure for prediction of ballasted track profile degradation under railway traffic loading
}

\author{
K Nguyen, D I Villalmanzo, J M Goicolea and F Gabaldon
}

\begin{abstract}
A computational procedure is developed in the present paper, allowing the prediction of the ballasted track profile degradation under railway traffic loading. In this procedure, an integration of the short-term and long-term mechanical processes of track deterioration is taken into account, using a track degradation model. This degradation model is incorporated into a finite element code where two modes of calculation are implemented: the "implicit mode" concerns the short-term track deterioration, in which the hypoplastic model is used for the ballast layer and the dynamic response to an instantaneous train axle passage is obtained to serve as input data for the "explicit mode", which concerns the simulation of long-term track deterioration, using the accumulation model for ballast layer. The whole procedure is illustrated on the prediction of the ballasted track profile degradation of a track section of $100 \mathrm{~m}$. The results show a significant influence of the type of track geometry defects and the vehicle velocity on the evolution of track deterioration and the capability of the proposed procedure in reproducing the track profile degradation.
\end{abstract}

\section{Keywords}

track settlement, accumulation model, hypoplasticity, vehicle-track interaction

\section{Introduction}

The maintenance costs for railway infrastructure, in the case of traditional ballasted track, represent a considerable amount, of the order of $€ 25,000-30,000$ per kilometre per year. ${ }^{1}$ It is of course a priority to optimise these costs and achieve a reduction in maintenance costs due to track quality deterioration and permanent settlements in ballasted track, which increase with velocity, traffic loads, number of load cycles and other factors. To this day the maintenance planning still has a strongly empirical character that could open to faults and misjudgements, due to the necessary time to analyse all of the data from inspection or an insufficient and/or inadequate database, etc. Therefore, an accurate prediction of track quality degradation can be a useful tool for interpreting and planning maintenance while minimising error as much as possible.

The deterioration of the track can be produced in different components of the track, generally these components may be categorised into two groups: the superstructure and the substructure. According to Suiker ${ }^{2}$ the mechanical processes that originate track deterioration can be separated into two categories: (i) short-term mechanical processes and (ii) long-term mechanical processes. The first category describes the instantaneous, dynamic behaviour of railway track, as activated during the passage of one, or several train axles. The second category is characterised by a typically quasi-static time dependency, such as subgrade particle migration into the ballast layer, or long-term substructural settlements and long-term abrasion of rail profiles under a very large number of train axle passages. From the modelling point of view, it is convenient to separate the short-term mechanical processes and long-term mechanical processes. However, for an adequate assessment of the overall track performance the interaction between these processes should also be taken into account.

This study presents a computational procedure for the prediction of ballasted track profile degradation under railway traffic loading, in which the short-term

\footnotetext{
'Department of Continuum Mechanics and Structures, School of Civil Engineering, Technical University of Madrid, Spain

${ }^{2}$ Department of Construction, Eduardo Torroja Construction Science Institute, Spain

${ }^{3}$ ADIF, C/Titán, No 4-6, 28045, Madrid, Spain
}

\section{Corresponding author:}

K Nguyen, Department of Construction, Eduardo Torroja

Construction Science Institute, C/ Serano Galvache, No 4, 28033 ,

Madrid, Spain.

Email: khanh@mecanica.upm.es or khanh@ietcc.csic.es 
mechanical processes and the long-term mechanical processes have been integrated into a joint modelling procedure. In the rest of this paper, the research background is described after this introduction. Following this, the track degradation model used in this study and its numerical implementation into the finite element code are described. For the prediction of track profile degradation a working methodology of the calculation procedure and a coupled vehicle-track system are presented. The influence of the type of track geometry defects and vehicle velocity on the settlement evolution and dynamic response are evaluated and discussed. Furthermore, the prediction capability of the proposed methodology is verified by comparing the numerical evolution of track profile with the real evolution of the track profile.

\section{Research background}

The repetitive dynamic loading and unloading of track structures from train traffic is the main cause of track degradation, which can be produced in different components of the track. According to the origin, several types of deterioration can be distinguished, such as deterioration of track geometric quality, rail defects, wheel defects and/or fatigue and failure of superstructure materials. The control of track geometric quality is a very important task in the track maintenance. Its deterioration is generated as a consequence of the track settlement. In turn, the track settlement is a result of permanent deformation in the different layers that support the sleepers, such as the ballast, sub-ballast and subgrade. In agreement with the studies performed by Selig and Waters, ${ }^{3}$ the relative contribution of the ballast layer settlement represents about $50-70 \%$ of overall settlement (see Figure 1(a)). Furthermore, in good quality track that is already consolidated, Selig and Waters ${ }^{3}$ indicate that the contribution of the subgrade and the sub-ballast layer are no longer representative in the total settlement of the track. Only the zone of ballast layer affected by tamping process contributes for the settlement process of the track (see Figure 1(b)).

According to Dahlberg, ${ }^{4}$ among other authors, the ballasted track settlement occurs in two major phases.

- Phase I: takes place immediately after the tamping. The settlement is relatively fast until the gaps

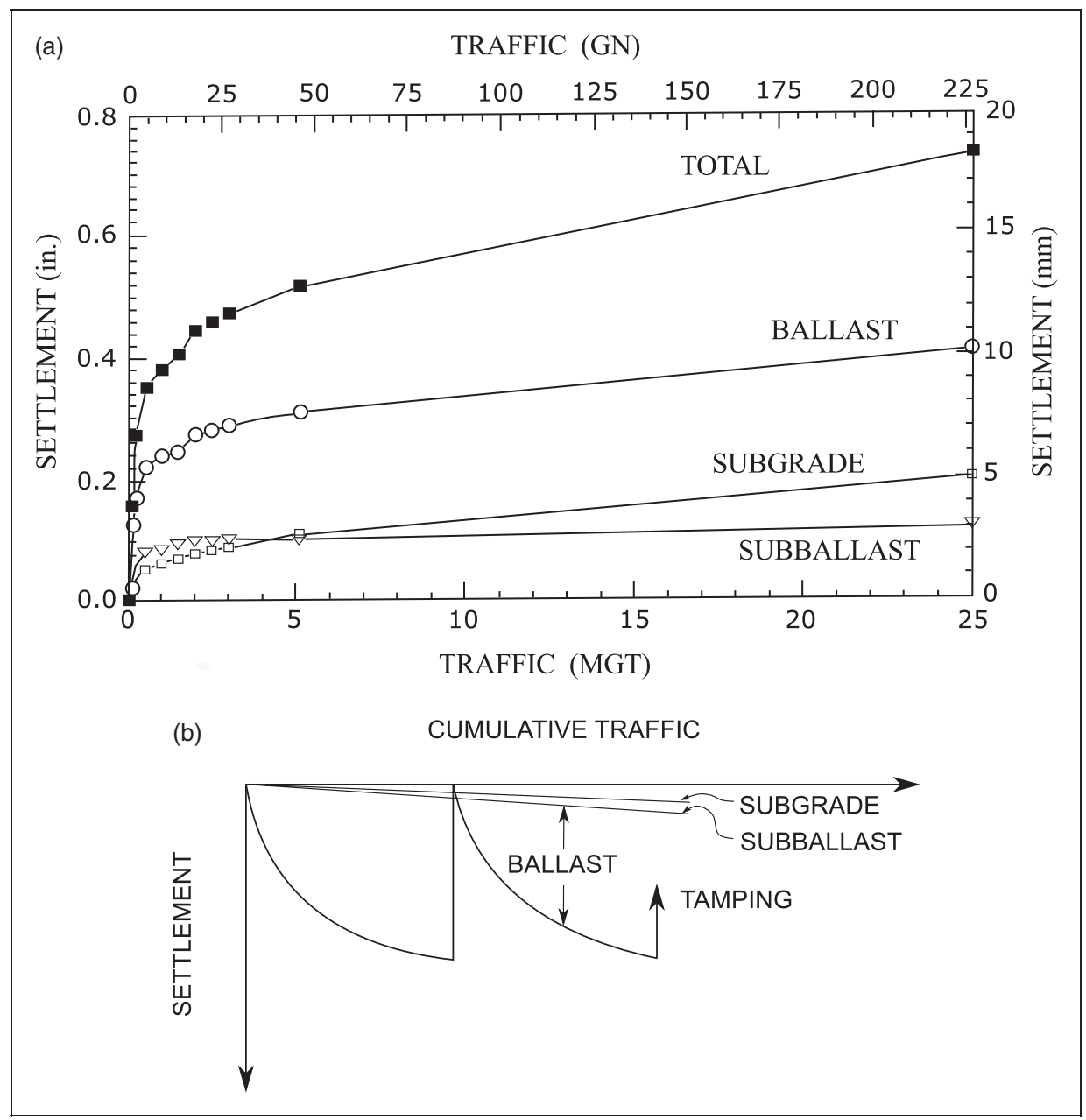

Figure I. Contributions of substructure to total track settlement: ${ }^{3}$ (a) in the new track; (b) in the consolidated track. 
between the ballast particles are reduced and the consolidation of ballast layer is achieved.

- Phase II: occurs after phase I. It represents a slower response with a relationship between settlement and number of loading cycles which is approximately linear. In this phase, important mechanisms of ballast and subgrade take place along lifetime, related mainly to their densification and inelastic behaviour.

Numerous authors have proposed models for estimation of track settlement and consequential track geometry deterioration. Most of those equations were based on the results of laboratory tests and measurements made on the track. Usually those equations involve empirical expressions that depend on parameters such as: maximum vertical pressure on the ballast, sleeper reaction force on the ballast, initial ballast deformation, sleeper elastic deflection, number of loading cycles and other constants. A power law in relation with the number of loading cycles has been proposed in the literature, ${ }^{5,6,7}$ while logarithmic formulations are used by a number of authors ${ }^{8,9}$ and other authors ${ }^{10,11,12}$ use a rate form. A detailed discussion of these empirical laws is given in Dahlberg. ${ }^{4}$ These laws are certainly easy to apply due to their simplicity, but represent some shortcoming. An essential problem is in fact that the characteristics of the applied loading cycle may not be sufficiently well captured. The load amplitude expressed in maximum vertical pressure on ballast is used in some works, ${ }^{8,13}$ but other characteristics of load such as the loading path, loading frequency are not taken into account. The ballast quality, initial track conditions and stiffening effects due to the densification are also not included in these laws. Furthermore, almost all of those laws are empirical formulations and not based on a continuum mechanical approach, therefore, the implementation of those laws in the finite element code presents consistency problems in the solution.

In order to better understand the mechanical processes that form the basis of track performance and track deterioration, a methodology for granular materials under large amplitude cyclic loading was proposed by Suiker and de Borst. ${ }^{2,14}$ The long-term behaviour of ballast is based on a shakedown concept, in which it is considered that no permanent deformations occur if the cycle load level is sufficiently small. In this constitutive model, the permanent deformation is generated by two separate mechanisms, frictional sliding and volumetric compaction, which are described through the use of two state variables in a classical plasticity framework. The Suiker model is certainly seen as an elegant law for predicting the strain accumulation behaviour of ballast material subjected to cyclic loading. This model is a purely mechanical approach, which avoids the consistency problems in solution that are found with the empirical laws. However, the Suiker model is developed on the basis of axisymmetric stress conditions. Therewith its application, in fact, is limited to two-dimensional or axisymmetric problems and cannot be applied directly to dynamic problems. According to Suiker and de Borst, ${ }^{14}$ it is necessary to translate the dynamic response to an instantaneous train axle passage into the quasi-static loading in order to apply this model to simulate the long-term track deterioration.

\section{Track settlement model}

The track settlement model used in this study is based on the model proposed by Niemunis et al. ${ }^{15}$ This model is a semi-explicit procedure, which is formed by the combination of two constitutive laws: a hysteretic model and an accumulation model. The hysteretic model is used in the so-called "implicit mode" to obtain the suitable stress and strain state in the material due to the quasi-static or dynamic loading. The accumulation model is applied in the so-called "explicit mode", using the information recorded in the previous step to estimate the increment of strain or of stress due to an increment of number of loading cycles $\Delta N$. Depending on the boundary conditions the accumulation model leads to an accumulation of stress or strain. In the case of accumulation of strain, the strain follows the average accumulation curve as given in Figure 2.

\section{Accumulation model}

The accumulation model was developed at the Ruhr University of Bochum since on the basis of numerous laboratory test results and based on the model proposed by Sawicki and Swidzinski. ${ }^{17}$ Proposals to capture multidimensional strain loops are made and several ideas to consider the strain amplitude $\varepsilon^{\text {ampl }}$ are presented in several publications. ${ }^{15,16,18-21}$

The basic structure of the accumulation model is similar to a creep law but instead of time $t$ the number of cycles $N$ is used. The general stress-strain relationship is expressed by the following form:

$$
\stackrel{\circ}{\boldsymbol{\sigma}}=\mathbf{E}:\left(\mathbf{D}-\mathbf{D}^{a c c}\right)
$$

Therein $\stackrel{\circ}{\sigma}$ is the objective Jaumann stress rate, $\mathbf{E}$ a stress-dependent elastic stiffness tensor, D the strain rate and $\mathbf{D}^{a c c}$ the rate of strain accumulation.

The rate of strain accumulation $\mathbf{D}^{a c c}$ depends on an important number of factors, but can be approximated by the following form:

$$
\mathbf{D}^{a c c}=\mathbf{m} f_{\mathrm{ampl}} \dot{f}_{N} f_{p} f_{e} f_{Y} f_{\pi}
$$

being $\mathbf{m}$ a tensorial direction of accumulation and six functions that consider the following influence:

- $f_{\text {ampl, }}$ strain amplitude $\varepsilon^{\mathrm{ampl}}$

- $\dot{f}_{N}$, number of cycles $N$; 


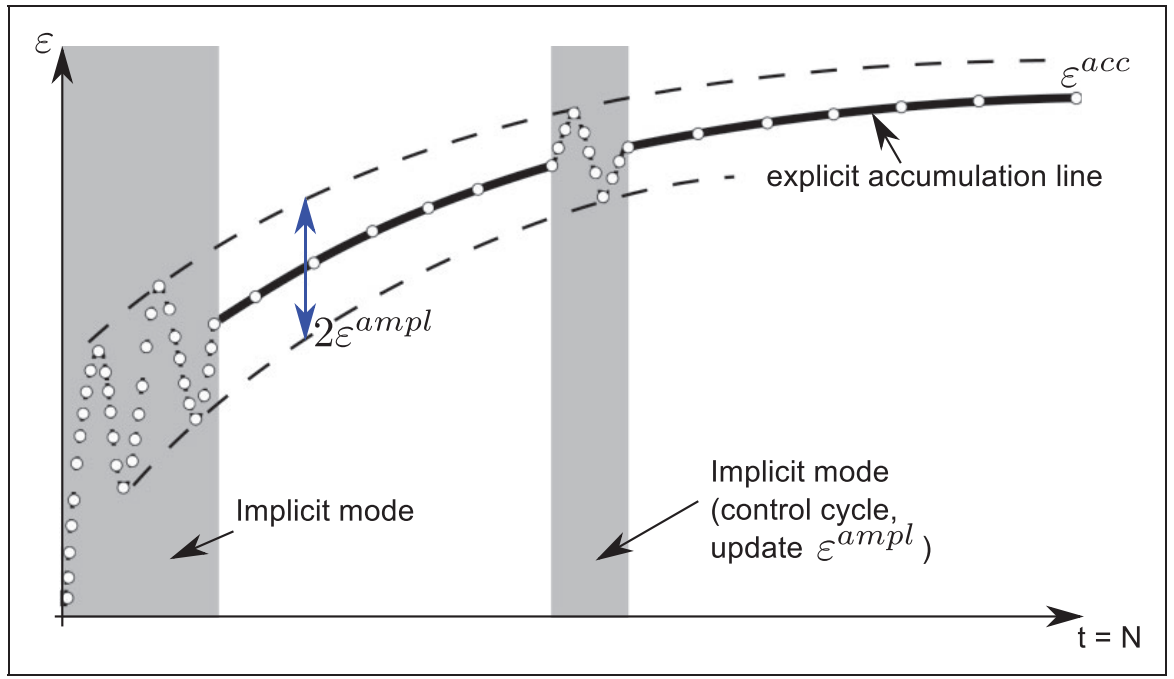

Figure 2. Scheme of the calculation of accumulation procedure (adapted from Wichtmann ${ }^{16}$ ).

- $f_{e}$, void ratio $e$;

- $f_{p}$, average mean pressure $p^{a v}$;

- $f_{Y}$, average stress ratio $\eta^{a v}=q^{a v} / p^{a v}$;

- $f_{\pi}$, polarisation changes.

A detailed discussion about these functions and the tensorial direction of accumulation is available in Wichtmann. ${ }^{16}$ In this paper, only the mathematical form of $\mathbf{m}$ and six functions are presented in Appendix A.

\section{Hypoplastic model}

Herein, a hypoplastic material model ${ }^{22,23}$ with an extension of the intergranular strain ${ }^{24}$ has been selected for the implicit calculation steps. Hypoplastic models have been developed as an alternative to elasto-plastic models. The model is incrementally nonlinear, rateindependent, does not need to define a yield surface, a flow rule or decompose the deformation into elastic and plastic part. The hypoplastic constitutive model is generally formulated by a single nonlinear tensorial equation that yields the objective Jaumann stress rate $\stackrel{\sigma}{\sigma}$ with the strain rate $\mathbf{D}$ :

$$
\stackrel{\circ}{\boldsymbol{\sigma}}=\mathcal{L}(\boldsymbol{\sigma}, e): \mathbf{D}+\mathbf{N}(\sigma, e)\|\mathbf{D}\|
$$

The fourth-order stiffness tensor $\mathcal{L}(\boldsymbol{\sigma}, e)$ and the second-order tensor $\mathbf{N}(\boldsymbol{\sigma}, e)$ are functions of the Cauchy stress tensor $\boldsymbol{\sigma}$ and void ratio $e$. These functions are the linear and nonlinear parts of the constitutive law, respectively. For completeness of this paper the mathematical representation of these functions given by Von Wolffersdorff $\mathrm{f}^{23}$ is attached in Appendix B. The term $\|\mathbf{D}\|=\sqrt{D_{i j} D_{i j}}$ makes the constitutive equation incrementally nonlinear. The void ratio is introduced as a state variable to take into account the effect of density material in its behaviour.
Since the mass is assumed to stay constant, the evolution of the void ratio $e$ can be determined by

$$
\dot{e}=(1+e) \operatorname{tr}(\mathbf{D})
$$

According to Niemunis and Herle, ${ }^{24}$ a shortcoming of the hypoplastic model in form (3) with respect to the simulation of cyclic loading is the so-called ratcheting which manifests itself in an unrealistically high rate of accumulation of deformation or stress. In order to improve the description of the behaviour of granular materials and, in particular, their response to cyclic loading, a new state variable was introduced by Niemunis and Herle ${ }^{24}$ and was the concept of intergranular strain as an extension of hypoplasticity. The so-called intergranular strain tensor $\boldsymbol{\delta}$ is thought to represent the deformation of an interface layer between granular particles. The hypoplastic model in the extended form becomes

$$
\stackrel{\circ}{\sigma}_{i j}=\mathcal{M}_{i j k l}(\boldsymbol{\sigma}, \mathbf{D}, \boldsymbol{\delta}, e) \mathrm{D}_{k l}
$$

with $\mathcal{M}_{i j k l}$ is the tensor that includes the tensors $\mathcal{L}$ and $\mathbf{N}$ from (3). The evolution equation of the intergranular strain tensor is determined by

$$
\dot{\boldsymbol{\delta}}=\mathbf{F}(\mathbf{D}, \boldsymbol{\delta})
$$

For detailed form of $\mathcal{M}_{i j k l}$ and $\mathbf{F}$, see Appendix B.

\section{Numerical implementation}

The presented track degradation model has been implemented as a user's material (user subroutine UMAT, see the ABAQUS User Subroutines Reference Manual) into FE program ABAQUS. ${ }^{25} \mathrm{~A}$ user material has been implemented and introduced within ABAQUS. The program ABAQUS uses an implicit time integration and a full Newton solution 


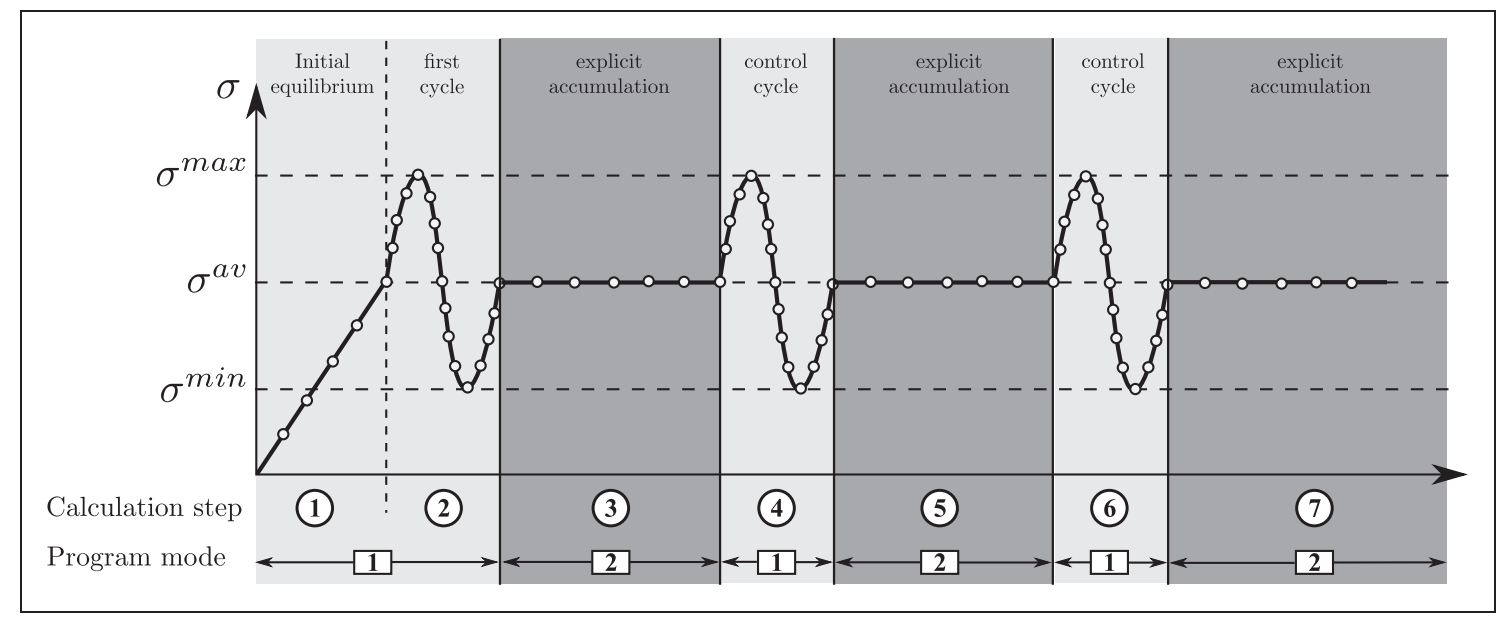

Figure 3. Assignment of calculation steps to program modes.

technique to solve (quasi-)static and dynamic problems. There are three essential outputs that are required to be updated within the UMAT subroutine. In particular, the Cauchy stresses STRESS $:=\boldsymbol{\sigma}$, the user-defined state variables STATEV $:=\mathbf{Q}$, and the tangent moduli DDSDDE $:=\partial \Delta \boldsymbol{\sigma} / \partial \Delta \boldsymbol{\varepsilon}$ (material Jacobian matrix) must be updated in every iteration (full Newton).

The UMAT subroutine implemented has two modes of operation.

1. Implicit mode: The program control is forwarded to this mode of the subroutine, in which the hypoplastic model with the extension of the intergranular strain (5) is implemented. This mode is used to obtain the initial state of equilibrium and perform the first load cycle and control cycles. During the calculation with this mode the state of stress and strain are recorded for subsequent calculation in the explicit mode.

2. Explicit mode: In this mode the calculation of accumulation according to equation (1) is carried out. Prior to the first increment in this mode the strain amplitude $\varepsilon^{\mathrm{ampl}}$ and the accumulation strain rate $\mathbf{D}^{a c c}$ have to be determined. The FE program redistributes stress in the course of equilibrium iteration. Depending on the boundary value problem it results in settlements or pseudo-relaxation.

The UMAT identifies the appropriate mode for the respective step by the step number specified in the input file. Figure 3 shows schematically how the calculation steps and program modes are assigned. It is sometimes practical to interrupt occasionally the explicit procedure using a so-called "control cycle" in which a load cycle is applied in the implicit mode. Such cycles are useful to update the strain amplitude $\varepsilon^{\mathrm{ampl}}$.

It is explained below how to obtain the Jacobian matrix for the track degradation model will be explained, which is composed by two constitutive models. Furthermore, an adaptive time integration for the constitutive equations will also be described. The size of substeps are controlled by a correct local error estimator.

\section{Consistent tangent moduli}

It can be noted that both the accumulation and the hypoplastic model have the constitutive equation in rate form. Therefore, the method to compute the consistent tangent moduli explained here is generally for both models. For the given stress tensor $\sigma\left(t_{n}\right)$ at equilibrium iteration $t_{n}$ and an initial estimation of strain increment $\Delta \boldsymbol{\varepsilon}$, the UMAT subroutine has to update the stress tensor $\sigma\left(t_{n}+\Delta t\right)$ at time $t_{n}+\Delta t$ and the Jacobian matrix (its derivative with respect to the strain increment). Thus, it is necessary to solve the following system of differential equations for $t_{n} \leqslant t \leqslant t_{n}+\Delta t$ :

$$
\begin{aligned}
\frac{d}{d t} \boldsymbol{\sigma} & =\mathbf{h}(\boldsymbol{\sigma}, \mathbf{D}, \mathbf{Q}) \\
\frac{d}{d t} \mathbf{Q} & =\mathbf{k}(\boldsymbol{\sigma}, \mathbf{D}, \mathbf{Q})
\end{aligned}
$$

where $\mathbf{Q}$ denotes the additional state variables of each model.

According to Fellin and Ostermann ${ }^{26}$ the stress increment and strain rate can be determined by $\Delta \boldsymbol{\sigma}=\boldsymbol{\sigma}\left(t_{n}+\Delta t\right)-\boldsymbol{\sigma}\left(t_{n}\right)$ and $\mathbf{D}=$ $\Delta \varepsilon / \Delta t$. Hence, the consistent tangent operator is expressed as

$$
\frac{\partial \Delta \boldsymbol{\sigma}}{\partial \Delta \boldsymbol{\varepsilon}}=\frac{\partial\left(\boldsymbol{\sigma}\left(t_{n}+\Delta t\right)-\boldsymbol{\sigma}\left(t_{n}\right)\right)}{\partial \Delta \boldsymbol{\varepsilon}}=\frac{1}{\Delta t} \frac{\partial \boldsymbol{\sigma}}{\partial \mathbf{D}}(\Delta t)
$$

From equation (8) in order to obtain the consistent tangent moduli it is necessary to differentiate equation (7) with respect to $\mathbf{D}$, which generates the following 
equations:

$$
\begin{aligned}
\frac{d}{d t} \frac{\partial \boldsymbol{\sigma}}{\partial \mathbf{D}}= & \frac{\partial \mathbf{h}}{\partial \boldsymbol{\sigma}}(\boldsymbol{\sigma}, \mathbf{D}, \mathbf{Q}): \frac{\partial \boldsymbol{\sigma}}{\partial \mathbf{D}}+\frac{\partial \mathbf{h}}{\partial \mathbf{D}}(\boldsymbol{\sigma}, \mathbf{D}, \mathbf{Q}) \\
& +\frac{\partial \mathbf{h}}{\partial \mathbf{Q}}(\boldsymbol{\sigma}, \mathbf{D}, \mathbf{Q}): \frac{\partial \mathbf{Q}}{\partial \mathbf{D}} \\
\frac{d}{d t} \frac{\partial \mathbf{Q}}{\partial \mathbf{D}}= & \frac{\partial \mathbf{k}}{\partial \boldsymbol{\sigma}}(\boldsymbol{\sigma}, \mathbf{D}, \mathbf{Q}): \frac{\partial \boldsymbol{\sigma}}{\partial \mathbf{D}}+\frac{\partial \mathbf{k}}{\partial \mathbf{D}}(\boldsymbol{\sigma}, \mathbf{D}, \mathbf{Q}) \\
& +\frac{\partial \mathbf{k}}{\partial \mathbf{Q}}(\boldsymbol{\sigma}, \mathbf{D}, \mathbf{Q}): \frac{\partial \mathbf{Q}}{\partial \mathbf{D}}
\end{aligned}
$$

As consequence of the complex expressions in the two above equations, they are determined by numerical differentiation:

$$
\frac{d}{d t}\left(\frac{\partial \boldsymbol{\sigma}}{\partial \mathbf{D}}\right)=\frac{\left\{\begin{array}{c}
\mathbf{h}(\boldsymbol{\sigma}(\mathbf{D}+\vartheta \mathbf{V}), \mathbf{D}+\vartheta \mathbf{V}, \mathbf{Q}(\mathbf{D}+\vartheta \mathbf{V})) \\
-\mathbf{h}(\boldsymbol{\sigma}, \mathbf{D}, \mathbf{Q})
\end{array}\right\}}{\vartheta}
$$

$$
\frac{d}{d t}\left(\frac{\partial \mathbf{Q}}{\partial \mathbf{D}}\right)=\frac{\left\{\begin{array}{c}
\mathbf{k}(\boldsymbol{\sigma}(\mathbf{D}+\vartheta \mathbf{V}), \mathbf{D}+\vartheta \mathbf{V}, \mathbf{Q}(\mathbf{D}+\vartheta \mathbf{V})) \\
-\mathbf{k}(\boldsymbol{\sigma}, \mathbf{D}, \mathbf{Q})
\end{array}\right\}}{\vartheta}
$$

being

$$
\boldsymbol{\sigma}(\mathbf{D}+\vartheta \mathbf{V})=\boldsymbol{\sigma}+\vartheta \frac{\partial \boldsymbol{\sigma}}{\partial \mathbf{D}}, \quad \mathbf{Q}(\mathbf{D}+\vartheta \mathbf{V})=\mathbf{Q}+\vartheta \frac{\partial \mathbf{Q}}{\partial \mathbf{D}}
$$

Consequently, equations (10) and (11) take the form

$$
\begin{aligned}
\frac{d}{d t}\left(\frac{\partial \boldsymbol{\sigma}}{\partial \mathbf{D}}\right)= & \frac{1}{\vartheta}\left(\mathbf{h}\left(\boldsymbol{\sigma}+\vartheta\left(\frac{\partial \boldsymbol{\sigma}}{\partial \mathbf{D}}\right), \mathbf{D}+\vartheta \mathbf{V}, \mathbf{Q}+\vartheta\left(\frac{\partial \mathbf{Q}}{\partial \mathbf{D}}\right)\right)\right. \\
& -\mathbf{h}(\boldsymbol{\sigma}, \mathbf{D}, \mathbf{Q})) \\
\frac{d}{d t}\left(\frac{\partial \mathbf{Q}}{\partial \mathbf{D}}\right)= & \frac{1}{\vartheta}\left(\mathbf{k}\left(\boldsymbol{\sigma}+\vartheta\left(\frac{\partial \boldsymbol{\sigma}}{\partial \mathbf{D}}\right), \mathbf{D}+\vartheta \mathbf{V}, \mathbf{Q}+\vartheta\left(\frac{\partial \mathbf{Q}}{\partial \mathbf{D}}\right)\right)\right. \\
& -\mathbf{k}(\boldsymbol{\sigma}, \mathbf{D}, \mathbf{Q}))
\end{aligned}
$$

where $\mathrm{V}_{i j}=\left(\delta_{i k} \delta_{j l}\right)_{k, l=1}$ for $1 \leqslant i \leqslant 3 ; 1 \leqslant j \leqslant 3$ and $\delta_{i k}$ is the Kronecker delta. To obtain a good approximation, the value of $\vartheta$ used should be sufficiently small. The value of $\vartheta$ recommended by Fellin and Ostermann ${ }^{26}$ is

$$
\vartheta=\max (1,\|\mathbf{D}\|) \cdot \sqrt{\mathrm{EPS}}
$$

in which EPS is the machine precision $\left(\mathrm{EPS} \approx 10^{-16}\right.$ for double precision arithmetic).

\section{Adaptive time step integration}

In order to solve numerically the differential equations (7) the explicit Runge-Kutta (2,3) integration method proposed by Bogacki and Shampine ${ }^{27}$ is implemented in the UMAT subroutine. The error and step size control is based on the Runge-KuttaFehlberg method, ${ }^{28}$ using the difference between the second- and third-order solution.

Considering that a super-vector $\mathbf{y}=(\boldsymbol{\sigma}, \mathbf{Q})$ will contain all the variables of the problem and $\mathbf{F}$ denotes the right-hand sides of equations (7), it must solve the following problem with the given initial value:

$$
\dot{\mathbf{y}}=\mathbf{F}(\mathbf{y}(t)), \quad \mathbf{y}\left(t_{n}\right)=\mathbf{y}_{n}
$$

An initial substep size $\Delta \tau$ is chosen, satisfying $0 \leqslant \Delta \tau \leqslant \Delta t$ where $\Delta t$ is the given increment by ABAQUS. The solutions that correspond to the second- and third-order accuracy of Taylor series expansion are computed:

$$
y_{\left(t_{n}+\Delta \tau\right)}^{(2)}=y_{\left(t_{n}\right)}+k_{2}
$$

$$
y_{\left(t_{n}+\Delta \tau\right)}^{(3)}=y_{\left(t_{n}\right)}+\frac{1}{6}\left(k_{1}+4 k_{2}+k_{3}\right)
$$

where

$$
\begin{aligned}
& k_{1}=\Delta \tau f\left(t_{n}, y_{\left(t_{n}\right)}\right) \\
& k_{2}=\Delta \tau f\left(t_{n}+\frac{\Delta \tau}{2}, y_{\left(t_{n}\right)}+\frac{k_{1}}{2}\right) \\
& k_{3}=\Delta \tau f\left(t_{n}+\Delta \tau, y_{\left(t_{n}\right)}-k_{1}+2 k_{2}\right)
\end{aligned}
$$

The local truncation error is estimated by the following form:

$$
\operatorname{err}_{\left(t_{n}+\Delta \tau\right)}=y_{\left(t_{n}+\Delta \tau\right)}^{(3)}-y_{\left(t_{n}+\Delta \tau\right)}^{(2)} \approx \mathcal{O}\left((\Delta \tau)^{3}\right)
$$

From equation 21 it can be seen that the local truncation error can be only estimated with a precision up to $\mathcal{O}\left((\Delta \tau)^{3}\right)$, but serves as a guide for selecting each substep $\Delta \tau$ when integrating from $t_{n}$ to $t_{n+1}$. According to Sloan ${ }^{29}$ it is difficult to monitor directly the global error, but it can be controlled by ensuring that the relative error for each substep is less than some specified tolerance. For a substep, the relative error can be defined as

$$
R_{t_{n}+\Delta \tau}=\frac{\left\|\operatorname{err}_{\left(t_{n}+\Delta \tau\right)}\right\|}{\left\|y_{\left(t_{n}+\Delta \tau\right)}^{(3)}\right\|}
$$

During the integration procedure the size of each substep is continually updated in such a way that

$$
R_{t_{n}+\Delta \tau} \leqslant \text { TOL }
$$

where TOL is error tolerance (typically in the range $10^{-2}$ to $\left.10^{-6}\right)$. Thus, $y_{\left(t_{n}+\Delta \tau\right)}^{(3)}$ is considered as solution 
for the given substep. The substep size $\Delta \tau_{\text {new }}$ for the next integration will be estimated with the following condition (see Figure 4):

$$
\Delta \tau_{\text {new }}=\min \left[2 \Delta \tau, 0.9 \Delta \tau\left(\frac{\mathrm{TOL}}{\operatorname{err}_{\left(\mathrm{t}_{\mathrm{n}}+\Delta \tau\right)}}\right)^{1 / 3}\right]
$$

If the estimated relative error is larger than TOL, the substep is rejected and the integration will be repeated with a smaller substep size given by

$$
\Delta \tau_{\text {new }}^{*}=\max \left[\frac{\Delta \tau}{4}, 0.9 \Delta \tau\left(\frac{\mathrm{TOL}}{\operatorname{err}_{\left(\mathrm{t}_{\mathrm{n}}+\Delta \tau\right)}}\right)^{1 / 3}\right]
$$

\section{Prediction of track profile degradation \\ Working methodology and fundamental assumptions}

In order to estimate the evolution of the track profile degradation due to a passing train, an iterative procedure, using the track degradation model for the ballast layer implemented into the program ABAQUS via the UMAT subroutine, is proposed and shown schematically in the flowchart in Figure 5. Initially, the irregularities profile together with all parameters of the vehicle-track system are given as input into the vehicle-track model. The short-term behaviour of the vehicle-track system is performed in the time domain, which involves the estimation of dynamic behaviour by a vehicle passing over the track with constant speed. This step is executed in the "implicit mode", in which the hypoplastic law is used for the ballast layer. During this step, the stress and strain path is recorded in each Gauss integration point of each ballast element in order to compute the rate of accumulation strain $\mathbf{D}^{a c c}$. The dynamic responses of vehicle-track system such as contact force, force transmitted by railpads, vibration in rail are also obtained. After the implicit step, the simulation is done in the "explicit mode", in which the long-term behaviour of the track is carried out in pseudo-time domain with the accumulation model used for the ballast layer. The rate of accumulation strain is estimated and then an increment of stress is computed for an increment of number of loading cycles $\Delta N$ (from now on, the number of loading cycles is understood as number of train passes) in agreement with (1). The finite element program will redistribute stress in the course of equilibrium iterations. Due to no external forces being applied in this step, it results in ballast settlement. The explicit calculation can be interrupted after certain number of cycles by the "control cycle" to update the rate of accumulation strain. In the control cycle, the new track profile due to the ballast settlement and the stress state of ballast layer are updated previously to the new dynamic calculation in implicit mode. A new loop of calculation is then begun.

The following assumptions are made in applying the proposed methodology.

- Only vertical load is taken into account for the track settlement. The lateral component, although relevant for track stability, is neglected in this work, due to the vertical track settlement being the largest result observed during the track degradation.

- Only ballast settlement is considered in the calculation. This assumes that the subgrade is already established, while the ballast layer is loosened by tamping. The contribution of ballast settlement is thus more significant.

- The ballast layer thickness is constant along the length of the track and is considered significantly smaller than the width of the ballast layer.

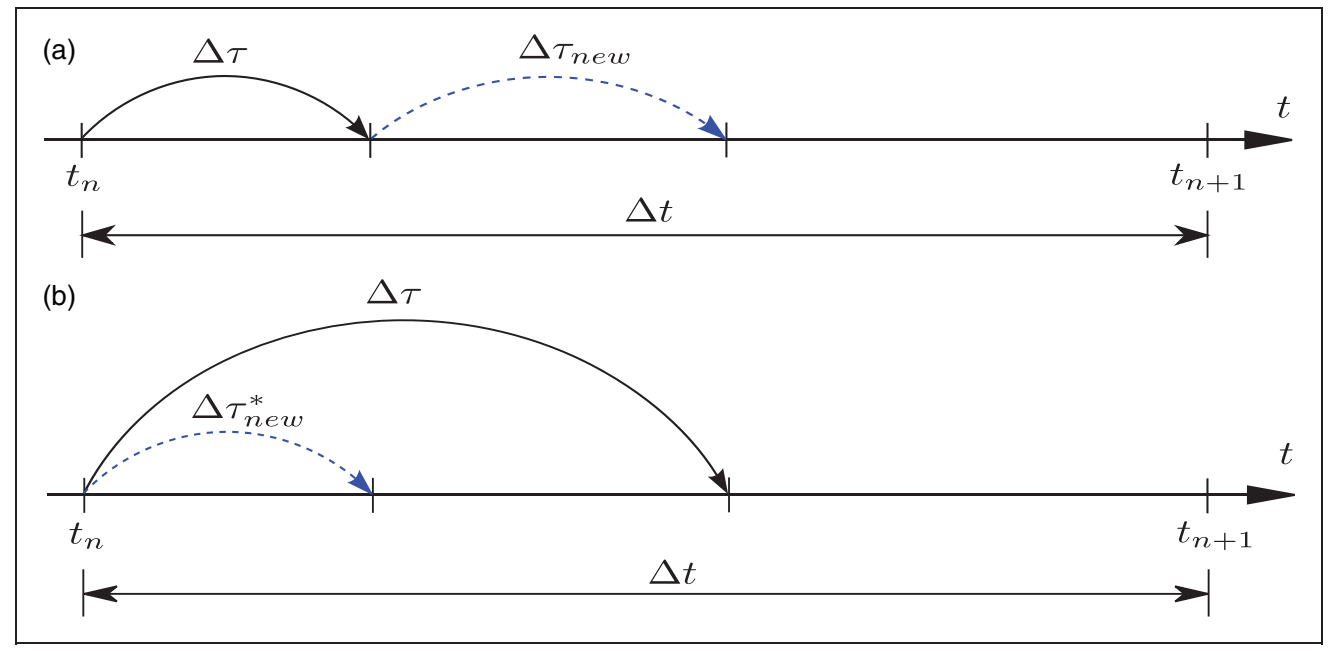

Figure 4. Diagram of selection of substep size: (a) accepted substep size, the integration advances with a new substep size $\Delta \tau_{\text {new; }}$; (b) rejected substep size, the integration will be repeated with a new smaller substep size $\Delta \tau_{\text {new }}^{*}$. 


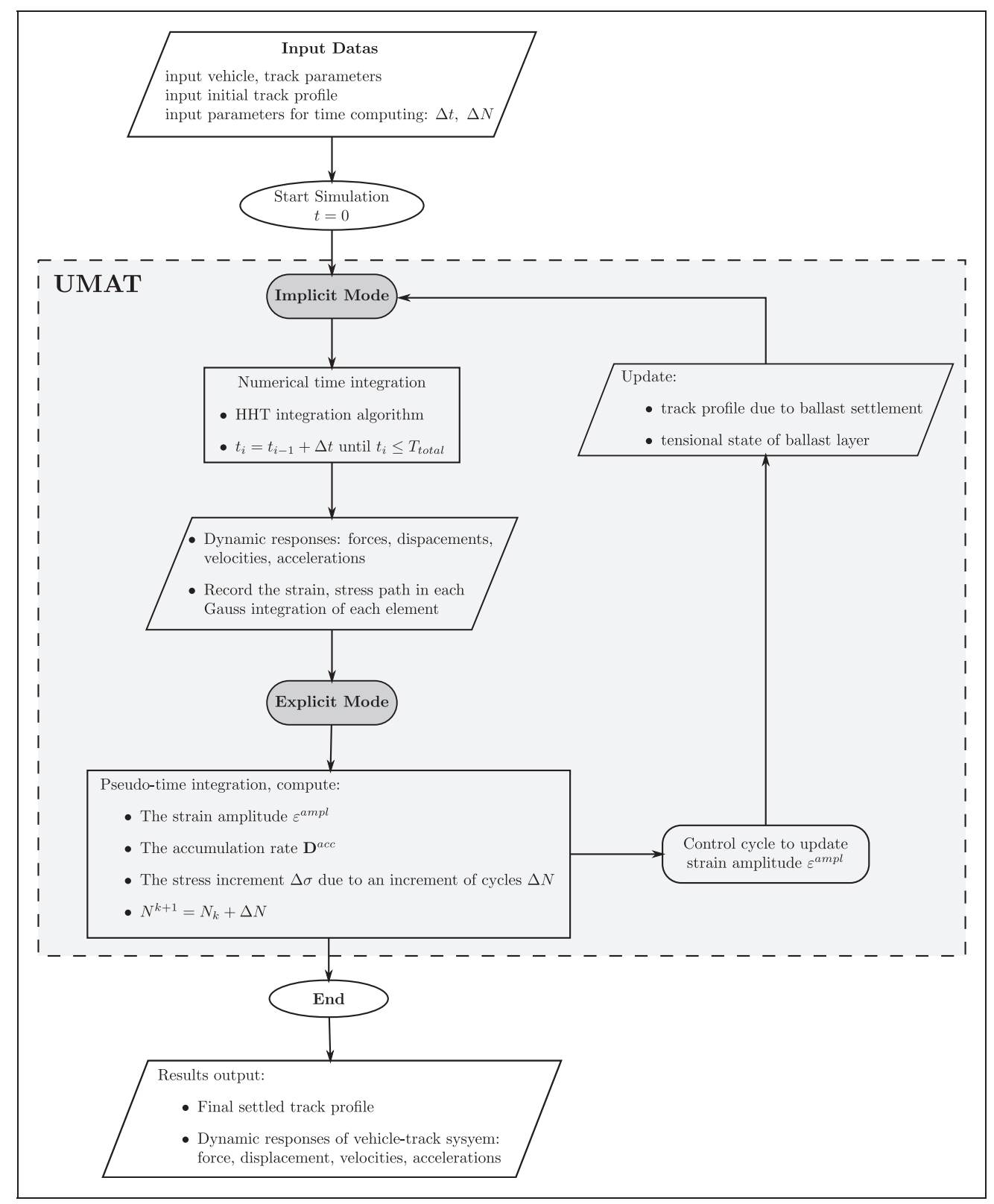

Figure 5. Flowchart of the working methodology for the calculation procedure.

With this consideration, the strain in the direction perpendicular to the vertical longitudinal plane may be neglected,$^{30}$ justifying the use of plane strain model for the ballast layer. It is acknowledged that in some circumstances the strain perpendicular to the vertical longitudinal plane may also be significant, which would require 3D models for detailed analysis.

- Environmental changes due to the weather are not included.

\section{Modelling vehicle-track system}

Figure 6 shows a detailed vehicle-track interaction model proposed to investigate the evolution of the track deterioration and assessing the vehicle-track dynamic responses along the degradation process.
Both vehicle and track are completely modelled in a finite element environment. According to Nguyen et al., ${ }^{31}$ a $2 \mathrm{D}$ vehicle model which includes the vertical dynamic effects of the primary and secondary suspensions, averaged among all wheels of the vehicle, is sufficiently accurate for predicting the vertical dynamic response for both the vehicle and the track. Therefore, the " $1 / 8$ vehicle model" has been adopted for this study. This model is represented by means of lumped masses, spring and damper elements, in fact, consisting of three mass components (mass of $1 / 2$ wheelset, mass of $1 / 4$ bogie and mass of $1 / 8$ car body) and of two levels of suspension (primary and secondary suspension), as shown in Figure 6. The vertical displacement is the only degree of freedom in each component. The vehicle concerned in this paper is the Euromed train (Talgo S130) with its parameters shown in Table 1. 


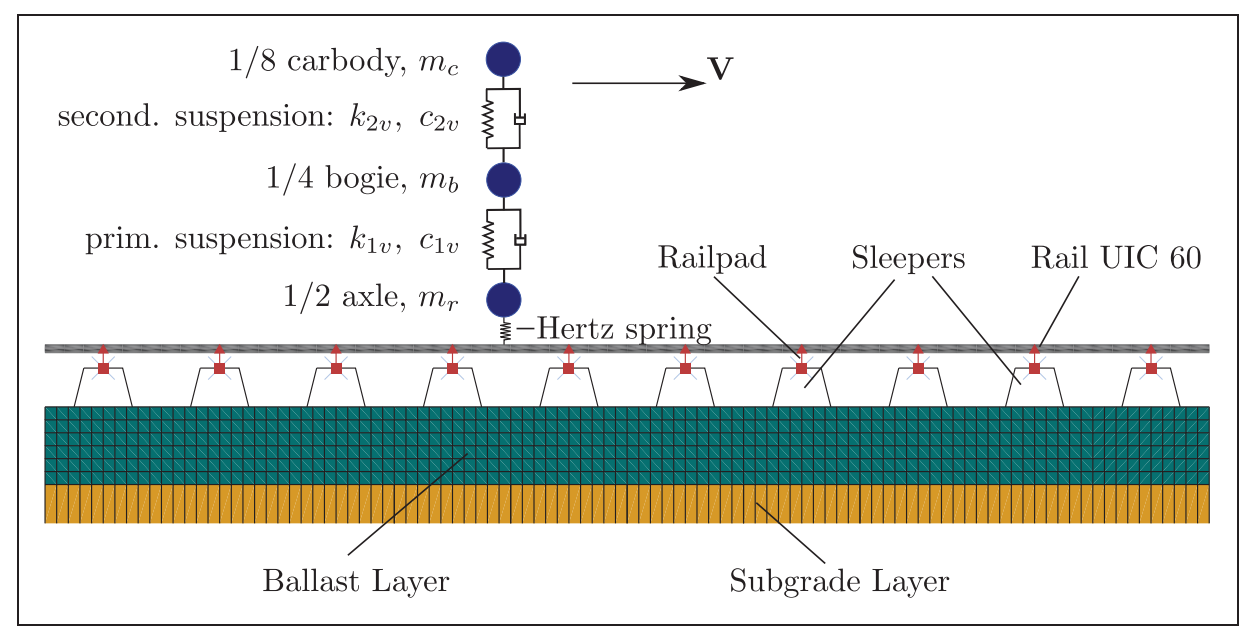

Figure 6. Two-dimensional numerical model of the vehicle-track system.

Table I. Parameters of the vehicle model.

\begin{tabular}{lll}
\hline Notation & Parameters & Value \\
\hline$M_{c}=8 m_{c}$ & Car body mass $(\mathrm{kg})$ & 57,200 \\
$M_{b}=4 m_{b}$ & Bogie mass $(\mathrm{kg})$ & 3600 \\
$M_{w}=2 m_{r}$ & $\begin{array}{l}\text { Wheelset mass }(\mathrm{kg}) \\
k_{2 v}\end{array}$ & $\begin{array}{l}\text { Secondary suspension } \\
\text { stiffness }(\mathrm{kN} / \mathrm{m})\end{array}$ \\
$c_{2 v}$ & $\begin{array}{r}\text { Secondary suspension } \\
\text { damper }(\mathrm{kNs} / \mathrm{m})\end{array}$ & 1900 \\
$k_{1 v}$ & $\begin{array}{c}\text { Primary suspension } \\
\text { stiffness }(\mathrm{kN} / \mathrm{m})\end{array}$ & 984.7 \\
$c_{1 v}$ & $\begin{array}{r}\text { Primary suspension } \\
\text { damper }(\mathrm{kNs} / \mathrm{m})\end{array}$ & 26 \\
\hline
\end{tabular}

The track submodel consists of the rail, the railpads, the sleepers, the ballast and subgrade layers. The rail is represented as a continuous beam with shear deformation that is discretely supported on the railpads modelled by the linear spring and damper elements. The sleepers are considered as rigid bodies with mass. These sleepers lie on the ballast layer and have contact with it. The contact formulation surface-surface ${ }^{25}$ is used and the Lagrange multiplier method is applied to the constraint enforcement. The contact between sleepers and ballast layer could be lost during the calculation, which allows us to study the effect of unsupported sleepers. The ballast layer is modelled by means of solid elements with plane strain, accounting for the different constitutive laws at each step of calculation: hypoplastic model for implicit mode and accumulation model for explicit mode. The subgrade layer is elastic material, modelled using the infinite elements as implemented in ABAQUS $^{25}$ to avoid wave reflections at the boundaries of the limited model.

The vehicle interacts with the track through the wheel-rail contact. Considering the geometry of the contact area between the round wheel and the rail, and under the assumptions that the wheel and rail are the same material with the elastic modulus $E$ and Poisson's ratio v, using Hertz's normal elastic contact theory $^{32}$ the relationship of wheel/rail force $\left(F_{v}\right)$ is determined by

$$
F_{v}=\delta_{v}^{3 / 2} C_{H} \text { where, } C_{H}=\frac{2 E}{3\left(1-v^{2}\right)}\left(r_{r} r_{w}\right)^{1 / 4}
$$

where $\delta_{v}$ is the vertical relative deformation, $r_{w}$ the wheel rolling radius and $r_{r}$ the head radius of the rail cross-section. A realistic common case of rail type UIC60 with $E=2.1 \times 10^{11} \mathrm{~N} / \mathrm{m}^{2}, \quad v=0.3$, $r_{r}=0.3 \mathrm{~m}$ and $r_{w}=0.455 \mathrm{~m}$ is considered in this study, for which the value of the Hertz's coefficient $C_{H}$ is $9.351 \times 10^{10} \mathrm{~N} / \mathrm{m}^{3 / 2}$.

A Hertzian spring is used for modelling the wheelrail contact. This spring is composed of two nodes: one node at the centre of the wheel and the other node on the rail. In this study the nonlinear behaviour according to equation (26) has been used for the Hertzian spring. The Lagrange multiplier method will be used for the contact constraint enforcement between the bottom node of Hertzian spring element and the rail surface.

\section{Simulation results}

In order to study the influence of some factors in the track deterioration, such as the type of track geometry defects and vehicle velocity, the track structure of Valls-Chilches section belonging to the line Valencia-Sant Vicent de Calders in Spain is selected. The main characteristics of the track structure adopted for this study, which are shown in Table 2

Prior to the performance of dynamic calculations, the static mechanical response of the finite element track model has been verified by checking the displacement profile of the rail under an axle load of $88.29 \mathrm{kN}$. Both the maximum displacement obtained of $0.65 \mathrm{~mm}$, within the expected normal range of $0.5-$ 
Table 2. Main characteristics of the track structure of the Valls-Chilches section (obtained from ADIF data).

\begin{tabular}{llll}
\hline Element & Type & Properties & Value \\
\hline Rail & UIC 60 & Cross-section area $(A)$ & $76.86 \mathrm{~cm}^{2}$ \\
& & Unit mass $(m)$ & $60.34 \mathrm{~kg} / \mathrm{m}$ \\
& & Moment of inertia $\left(I_{x x}\right)$ & $3055 \mathrm{~cm}^{4}$ \\
& & Moment of inertia $\left(I_{y y}\right)$ & $512.9 \mathrm{~cm}^{4}$ \\
Fastening & Elastic & Railpad stiffness $\left(k_{p}\right)$ & $100 \mathrm{MN} / \mathrm{m}$ \\
system & Vossloh & Railpad damping $\left(c_{p}\right)$ & $32 \mathrm{kN} \mathrm{s} / \mathrm{m}$ \\
Sleeper & & Sleeper length $(I)$ & $2.6 \mathrm{~m}$ \\
& Monobloc & Sleeper mass $\left(m_{t}\right)$ & $325 \mathrm{~kg}$ \\
& PR-90 & Sleeper width $\left(a_{t}\right)$ & $0.3 \mathrm{~m}$ \\
& & Sleeper height $\left(d_{2}\right)$ & $0.24 \mathrm{~m}$ \\
& & Sleeper spacing $\left(I_{s}\right)$ & $0.60 \mathrm{~m}$ \\
Ballast & Type 2 & Density $\left(\rho_{b}\right)$ & $1402 \mathrm{~kg} / \mathrm{m}^{3}$ \\
& & Coefficient of Los & $13.08 \%$ \\
& & Angeles abrasion & \\
& & Ballast height & $0.35 \mathrm{~m}$ \\
\hline
\end{tabular}

$2.0 \mathrm{~mm}$, and the profile (not shown for brevity) reflect the expected behaviour.

The irregularity profile is initially introduced as input data into the vehicle-track model, which was obtained in the track geometry inspection realised by ADIF on the line Valencia-Sant Vicent de Calders in 2008. Two types of track geometry defect related to the maximum defects (peak values) and the standard deviation have been identified and used in this study in order to investigate the influence of track geometry defects on the dynamic responses of vehicletrack system and the evolution of track settlement due to those dynamic effects. Figure 7 shows two initial track irregularity profiles used in the numerical simulation. It is considered that those two profiles are obtained soon after the tamping process.

The numerical simulations are carried out with the vehicle-track model described above, using the proposed methodology. The Hilber-Hughes-Taylor (HHT) time integration method ${ }^{33}$ is used to solve the transient problem in the time domain. A constant time step $\Delta t=0.2 \times 10^{-3} \mathrm{~s}$ is used in this dynamic calculation. Furthermore, a range of vehicle velocities ranging from 160 to $220 \mathrm{~km} / \mathrm{h}$, in increments of $10 \mathrm{~km} / \mathrm{h}$, are considered in order to study the influence of vehicle velocity. The calculation of settlement is executed immediately after the dynamic calculation and done in pseudo-time with an increment of number of train passes $\Delta N=50$. During the simulation, the calculation of settlement is interrupted by several control cycles, in which the dynamic calculation is performed to update the dynamic response due to the track profile change. The total number of train passes for the simulation is 50,000 which corresponds to the total traffic volume of trains circulating on this line over 2 years. The following results have been obtained and will be discussed below:
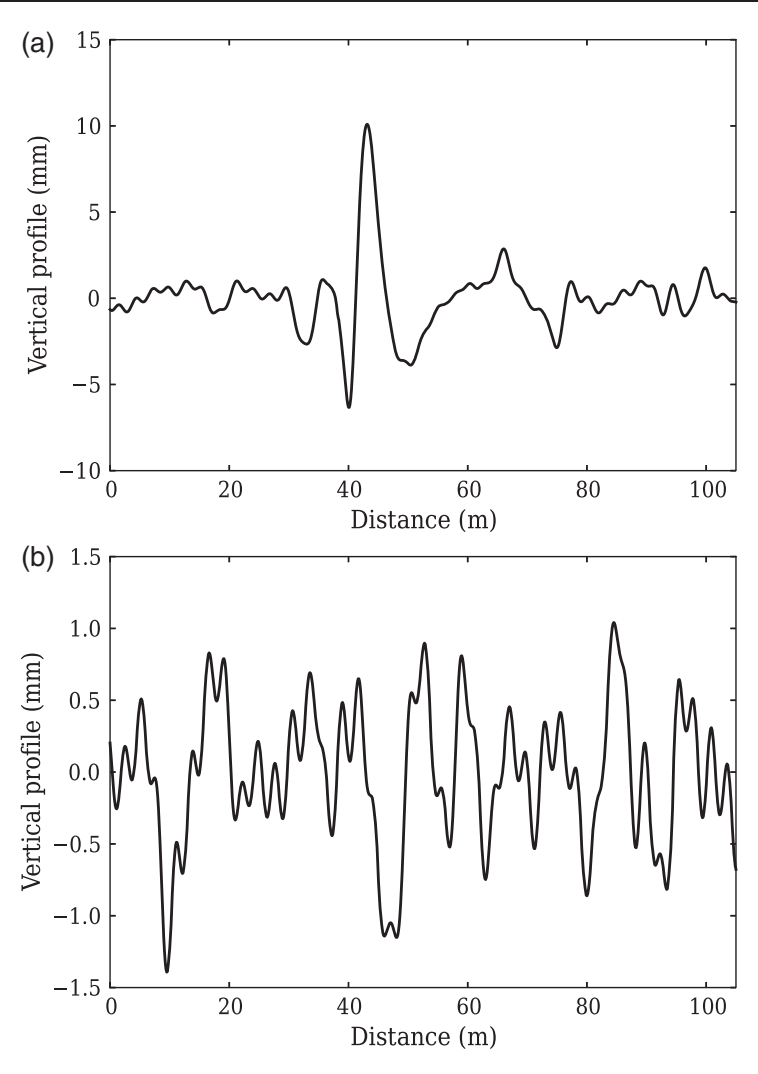

Figure 7. Initial track profile: (a) with isolated defect; (b) with distributed defect.

- track settlement evolution;

- contact force between wheel and rail;

- force transmitted by railpads to sleepers.

\section{Influence of track geometry defects}

It is known that the track geometry defects are the main excitation sources that may induce oscillations, vibrations and noise in the vehicle-track system. The track geometry is deteriorated as a consequence of those effects. In order to illustrate the influence of the different track geometry defects on the track settlement evolution, Figure 8 presents the evolution of vertical settlement along the track section for vehicle velocity $v=200 \mathrm{~km} / \mathrm{h}$. In all graphs, the track settlement is plotted for each 5000 train passes. It can be observed that the vertical settlement evolution is fairly uniform in case of the track profile with distributed defect, while a larger local settlement is generated in the case of the track profile with isolated defect as expected. Thus, the contact force between wheel and rail and the consequently force transmitted by railpads in the isolated defect zone are much greater than in the other zone with more distributed defects (see Figures 9 and 10). Furthermore, from Figure 9 it can be noted that the contact force obtained after 50,000 train passes increases considerably with respect to that obtained in the first cycle, even achieving loss of contact between wheel and rail. 


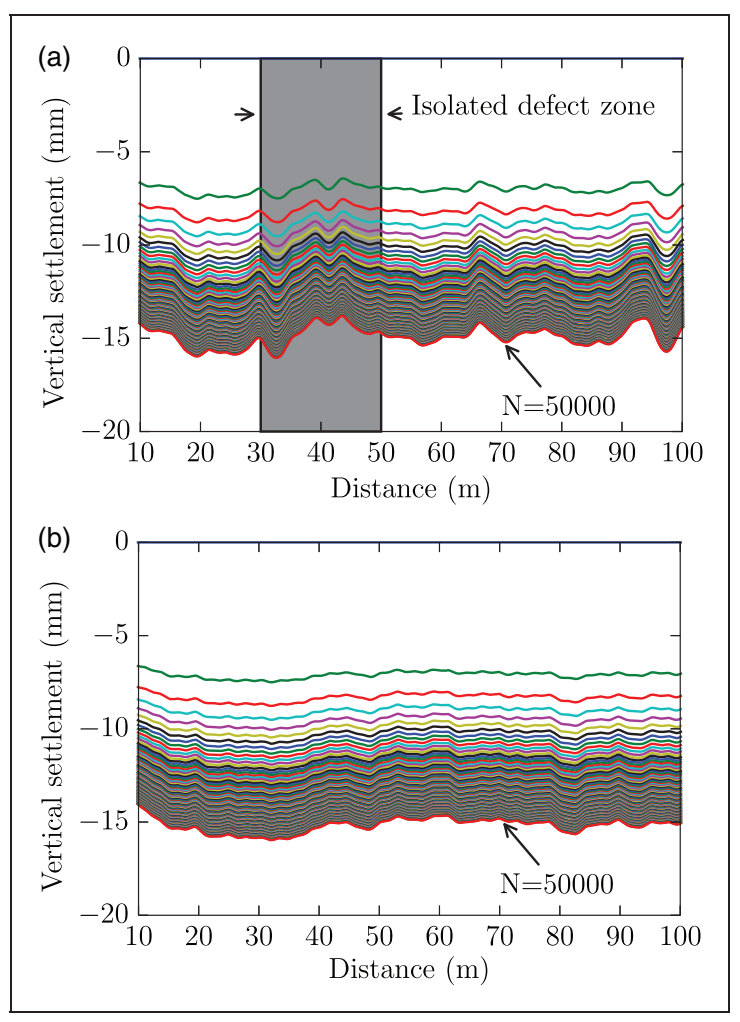

Figure 8. Evolution of the vertical settlement along the track section when $v=200 \mathrm{~km} / \mathrm{h}$ : (a) isolated defect; (b) distributed defect.

The other phenomenon observed in the numerical results is the load impact on the track due to unsupported sleepers, as shown in Figure 10. In this figure, the force transmitted by railpads is obtained in the control cycle (dynamic calculation) after 50,000 train passes. It can be seen that at the beginning of the dynamic calculation, there is preload in the railpads: some of those are in tension and the others are in compression. It is due to the redistribution of the self-weight of the super-structure of track when some sleepers may be completely unsupported due to the differential ballast settlement along track section. A higher force transmitted by railpads is achieved in the unsupported sleepers zone when the vehicle runs over the track. These forces can be twice as high as those obtained under normal conditions.

\section{Influence of vehicle velocity}

A range of vehicle velocities that corresponds to the real speeds over this track section, ranging from 160 to $220 \mathrm{~km} / \mathrm{h}$, in increments of $10 \mathrm{~km} / \mathrm{h}$, has been considered. The evolution of the standard deviation of the track section as a function of the number of train passes $(N)$ is presented in Table 3. It can be observed that the track quality deterioration grows as the vehicle velocity increases. In fact, the standard deviation value obtained after 50,000 train passes is $64 \%$ larger than the initial value for the largest velocity considered $v=220 \mathrm{~km} / \mathrm{h}$, and this value is $12 \%$

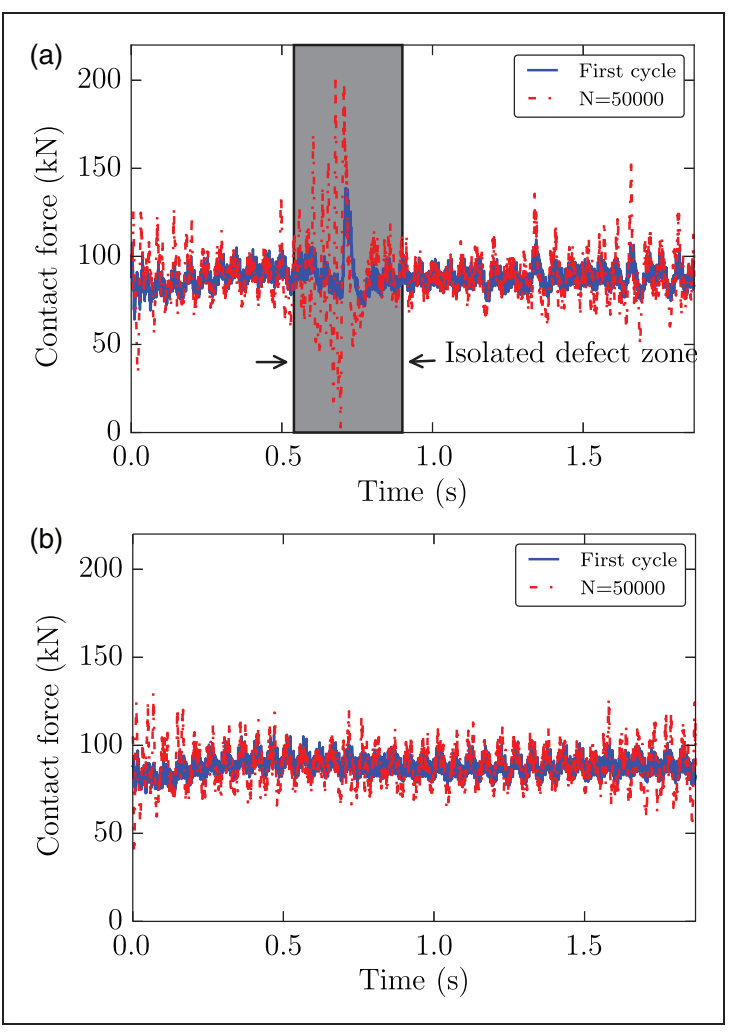

Figure 9. Contact force between wheel and rail for $v=200 \mathrm{~km} / \mathrm{h}$ : (a) isolated defect; (b) distributed defect.

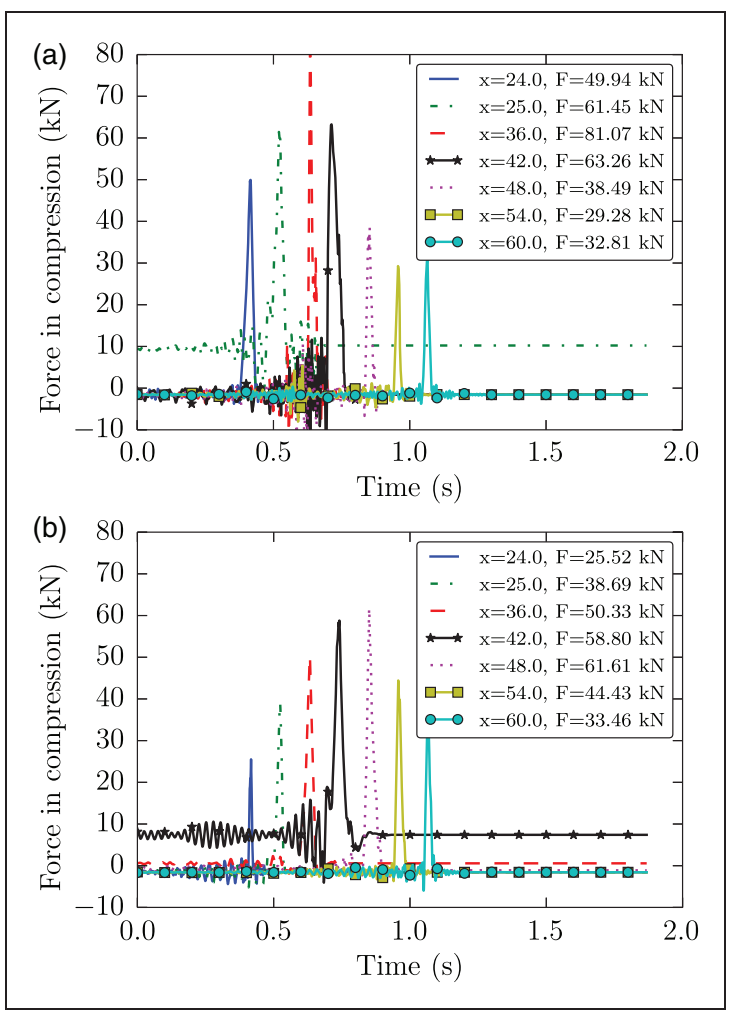

Figure 10. Force transmitted by railpads for $v=200 \mathrm{~km} / \mathrm{h}$ after 50,000 train passes: (a) isolated defect; (b) distributed defect. Here $x$ refers to longitudinal position of railpads and $F$ is maximum force. 
Table 3. Standard deviation obtained in different numbers of train passes for different vehicle velocities.

\begin{tabular}{|c|c|c|c|c|c|c|c|}
\hline \multirow{2}{*}{$\begin{array}{l}N \\
\text { (passes) }\end{array}$} & \multicolumn{7}{|c|}{ Standard deviation $\sigma(\mathrm{mm})$} \\
\hline & $v=160$ & $v=170$ & $v=180$ & $v=190$ & $v=200$ & $v=210$ & $v=220$ \\
\hline 0 & 0.475 & 0.475 & 0.475 & 0.475 & 0.475 & 0.475 & 0.475 \\
\hline 5000 & 0.596 & 0.602 & 0.615 & 0.629 & 0.630 & 0.643 & 0.662 \\
\hline 10000 & 0.628 & 0.631 & 0.642 & 0.658 & 0.660 & 0.678 & 0.696 \\
\hline 15000 & $0.64 I$ & 0.646 & 0.658 & 0.676 & 0.678 & 0.699 & 0.716 \\
\hline 20000 & 0.652 & 0.658 & 0.670 & 0.690 & 0.692 & 0.713 & 0.730 \\
\hline 25000 & 0.660 & 0.669 & 0.680 & 0.700 & 0.703 & 0.725 & 0.742 \\
\hline 30000 & 0.671 & 0.678 & 0.688 & 0.709 & 0.712 & 0.735 & 0.751 \\
\hline 35000 & 0.680 & 0.686 & 0.694 & 0.716 & 0.720 & 0.743 & 0.759 \\
\hline 40000 & 0.687 & 0.692 & 0.700 & 0.723 & 0.727 & 0.750 & 0.766 \\
\hline 45000 & 0.692 & 0.697 & 0.705 & 0.728 & 0.733 & 0.756 & 0.772 \\
\hline \multirow[t]{3}{*}{50000} & 0.698 & 0.702 & 0.710 & 0.733 & 0.738 & 0.762 & 0.777 \\
\hline & \multicolumn{7}{|c|}{ Alert limit by EN I3848-5:2008 ${ }^{34} \sigma_{L}(\mathrm{~mm})$} \\
\hline & 1.4 & 1.2 & 1.2 & 1.2 & 1.2 & 1.2 & 1.0 \\
\hline
\end{tabular}

larger than the same value obtained for the vehicle velocity $v=160 \mathrm{~km} / \mathrm{h}$. Compared with the alert limit established by EN 13848-5:2008, ${ }^{34}$ the value of standard deviation of the studied track section is still below this alert limit, therefore, the regularly planned maintenance operation is not necessary.

With respect to the dynamic responses during the vehicle-track interaction, the dynamic amplification factor $\phi$ is used to interpret the results in dimensionless form:

$$
\phi=\frac{F_{\text {dyn }}}{F_{\text {sta }}}
$$

where $F_{\text {sta }}$ is the static response and $F_{\text {dyn }}$ is the maximum dynamic response. Figure 11 illustrates the dynamic amplification factors of wheel-rail contact force obtained in different control cycles for the range of vehicle velocity. It may be observed that the dynamic response of vehicle-track system increases with the vehicle speed. A significant dynamic amplification can be generated when the vehicle runs over the track with isolated defects at high speed (1.78 for $v=220 \mathrm{~km} / \mathrm{h}$ in initial profile) and, in particular, this value shows very large values after 50,000 train passes $(2.42$ for $v=220 \mathrm{~km} / \mathrm{h})$. In general, the amplification factor increases with speed. However, this is not always the case, and in some situations, critical velocities may be reached.

\section{Verification of prediction capability}

To verify the capacity of prediction of track profile degradation of the proposed methodology in this paper, using the 2D model of the vehicle-track system shown in Figure 6, the predicted evolution of the track geometry obtained by numerical simulation will be compared with the real evolution of track geometry. For this analysis, a different track section is selected, for which

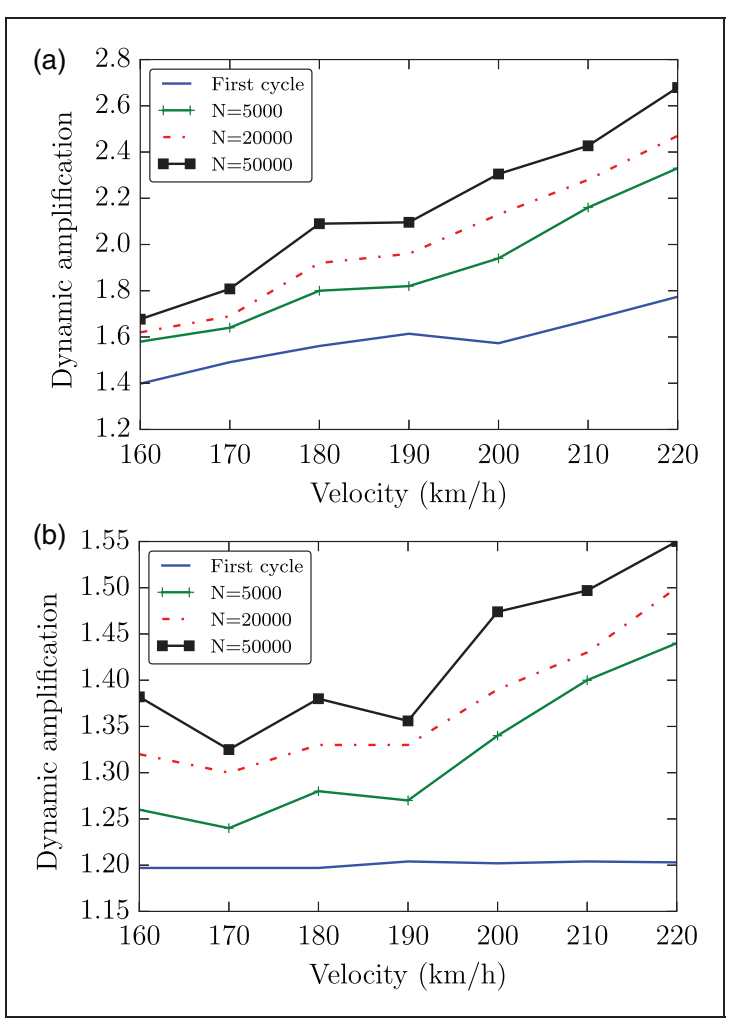

Figure II. Dynamic amplification factor of contact force between wheel and rail in different train passes: (a) isolated defect; (b) distributed defect.

field measurement information was available: the Matapozuelos-Valdestillas track section belonging to the Madrid-Hendaya line in Spain, modelled with the standard train traffic mix. The real evolution of vertical track profile are obtained from different inspection campaigns from 2008 to 2010 by the Spanish Organization of Railway Infrastructure (ADIF), as shown in Figure 12(a). According to ADIF's 


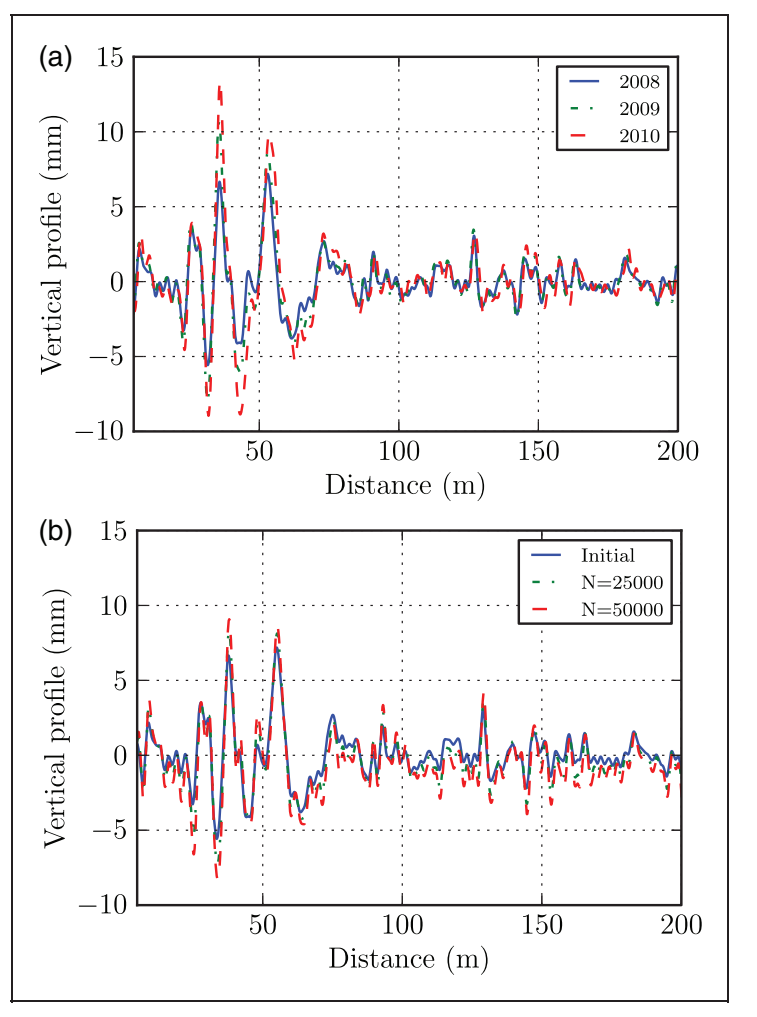

Figure 12. Evolution of the vertical track profile: (a) data obtained from inspection; (b) data obtained from the numerical simulation.

information, no maintenance work was done in this period, and there are about 25,000 trains circulating on this line per year with a maximum speed of $120 \mathrm{~km} / \mathrm{h}$. The main adopted characteristics of train and track are listed in Table 4. The numerical simulation is performed using the proposed methodology, with the total number of 50,000 train passes that corresponds to the total traffic volume of this period 2008-2010. The vehicle runs over the track with constant speed of $120 \mathrm{~km} / \mathrm{h}$. A constant time step $\Delta t=0.2 \times 10^{-3} \mathrm{~s}$ is used in dynamic calculation and an increment of number of train passes $\Delta N=50$ are used in the simulation.

It is noted that the value of track profile obtained in the inspection campaign is relative, while the results obtained by numerical simulation are absolute values of vertical track settlement in the global coordinate system. Therefore, in order to compare the numerical results with the real profile, a relative vertical profile is determined by using the double integration of the acceleration of the wheel obtained in the numerical simulation. ${ }^{35}$ Figure 12 (b) shows the relative vertical profile of the track from the numerical simulation at different number of train passes that correspond to each year of inspection. It can be seen that there is small difference in the peak value between the real and numerical results, but in general the vertical profile obtained by simulation is closed to the real value. If it takes into account that some simplifications in the modelling and properties of vehicle and ballast layer have been adopted for numerical simulation, the numerical results could be considered as a good
Table 4. Main parameters of train and track used in the validation of the model.

\begin{tabular}{|c|c|c|}
\hline Notation & Parameter & Value \\
\hline \multicolumn{3}{|c|}{ Vehicle system } \\
\hline$M_{c}=8 m_{c}$ & Mass of car body (kg) & 59500 \\
\hline$M_{b}=4 m_{b}$ & Mass of bogie $(\mathrm{kg})$ & 3100 \\
\hline$M_{w}=2 m_{r}$ & Mass of wheelset $(\mathrm{kg})$ & 1577 \\
\hline$k_{2 v}$ & $\begin{array}{l}\text { Secondary suspension } \\
\text { stiffness }(\mathrm{kN} / \mathrm{m})\end{array}$ & 368 \\
\hline$c_{2 v}$ & $\begin{array}{l}\text { Secondary suspension } \\
\text { damper }(\mathrm{kNs} / \mathrm{m})\end{array}$ & 12.7 \\
\hline$k_{\text {Iv }}$ & $\begin{array}{l}\text { Primary suspension } \\
\text { stiffness }(\mathrm{kN} / \mathrm{m})\end{array}$ & 981 \\
\hline$c_{I v}$ & $\begin{array}{r}\text { Primary suspension } \\
\text { damper }(\mathrm{kNs} / \mathrm{m})\end{array}$ & 32.27 \\
\hline \multicolumn{3}{|c|}{ Track system } \\
\hline A & $\begin{array}{l}\text { Cross section area } \\
\text { of rail UIC } 54\left(\mathrm{~cm}^{2}\right)\end{array}$ & 6977 \\
\hline $\mathrm{m}$ & Unit mass of rail UIC $54(\mathrm{~kg} / \mathrm{m})$ & 54.77 \\
\hline$I_{x x}$ & Moment of inertia of UIC $54\left(\mathrm{~cm}^{4}\right)$ & 2337.9 \\
\hline$I_{y y}$ & Moment of inertia of UIC $54\left(\mathrm{~cm}^{4}\right)$ & 419.2 \\
\hline$k_{p}$ & Railpad stiffness (MN/m) & 140 \\
\hline$c_{p}$ & Railpad damping (kN s/m) & 45 \\
\hline I & Sleeper length $(\mathrm{m})$ & 2.6 \\
\hline$m_{t}$ & Sleeper mass (kg) & 325 \\
\hline$a_{t}$ & Sleeper width (m) & 0.3 \\
\hline$h_{t}$ & Sleeper height (m) & 0.24 \\
\hline$l_{s}$ & Sleeper spacing $(\mathrm{m})$ & 0.60 \\
\hline \multirow[t]{2}{*}{$\rho_{b}$} & Ballast density $\left(\mathrm{kg} / \mathrm{m}^{3}\right)$ & 1395 \\
\hline & $\begin{array}{l}\text { Ballast coefficient } \\
\text { of Los Angeles abrasion (\%) }\end{array}$ & 9.3 \\
\hline$h_{b}$ & Ballast height $(\mathrm{m})$ & 0.35 \\
\hline
\end{tabular}

approximation, demonstrating the capacity of the proposed methodology.

\section{Conclusions}

This work describes a computational procedure for the prediction of ballasted track profile degradation under railway traffic loading, in which a track settlement model combined by two constitutive laws (hypoplastic and accumulation model) has been used and implemented into the finite element code ABAQUS. Moreover, to evaluate the dynamic effects generated during the vehicle-track interaction in the track settlement, a 2D coupled vehicle-track model was used. The wheel-rail contact was considered in the vehicle-track interaction, using a nonlinear Hertzian spring. A nonlinear contact interaction is also considered between the sleepers and the ballast layer. The main results obtained in this study are as follows.

- The permanent deformation of the ballast layer depends on the dynamic loading transmitted to 
this layer, and on the number of train passes. This deformation accumulation increases with the number of train passes and causes the continuous deterioration of track geometry quality. A faster deterioration is observed in the zone with isolated defects.

- As a consequence of the track geometry deterioration, the dynamic force on the track increases even more with the number of train passes, and in turn, the increasing dynamic force will damage the track geometry quality further, leading to a cyclic feedback process.

- Vehicle velocity is an important factor that has considerable influence on the track geometry deterioration. Greater speeds will induce higher dynamic forces on the track and the track deterioration will be faster.

- Unsupported sleepers due to the differential ballast settlement are observed during the simulation, producing increased force transmitted by railpads to the ballast layer than that obtained in normal conditions.

The evolution of the track profile degradation obtained by numerical simulation showed a good agreement with the site data on the selected track section of Matapozuelos-Valdestillas. This proves the prediction capability of the proposed methodology for reproducing track degradation. However, the verification carried out in this paper is only available for this particular case. Further work including a complete and systematic measurement program would be needed to provide a complete validation.

\section{Declaration of Conflicting Interests}

The author(s) declared no potential conflicts of interest with respect to the research, authorship, and/or publication of this article.

\section{Funding}

The author(s) disclosed receipt of the following financial support for the research, authorship, and/or publication of this article: This work was supported by the "Ministerio de Ciencia e Innovación" of the Spanish Government through subprogram INNPACTO and project VIADINTEGRA (reference IPT-370000-2010-012) and to the support provided by ADIF and Technical University of Madrid, Spain. K. Nguyen would like to express his gratitude to AECID for a $\mathrm{PhD}$ grant during this study.

\section{References}

1. López-Pita A, Teixeira P, Casas C, et al. Maintenance costs of high-speed lines in Europe: state of the art Transport Res Record 2008; 2043: 13-19.

2. Suiker A. The Mechanical Behavior of Ballasted Railway Tracks. PhD Thesis, Deft Technical University, Deft, The Netherlands, 2002.

3. Selig E and Waters J. Track Geotechnology and Substructure Management. London: Thomas Telford Services Ltd, 1994.
4. Dahlberg T. Some railroad settlement models - a critical review. Proc IMechE Part F 2001; 215: 289-301.

5. Shenton MJ. Ballast deformation and track deterioration. In ICE conference on track technology for the next decade. Nottingham: Thomas Telford Ltd, 1984, pp.253-265.

6. Sato Y. Japanese studies on deterioration of ballasted track. Vehicle Syst Dynam 1995; 24(S1): 197-208.

7. Li D and Selig ET. Cumulative plastic deformation for fine-grained subgrade soils. J Geotech Eng 1996; 122(12): 1006-1013.

8. Henn W. Auswirkung von Oberbauform und Betriebsbelastung auf die Veränderung der Gleishöhenlage. Mitteilungen des Prüfamtes für Bau von Landverkehrswegen. Technical Report 30, Technical University of Munich, Munich, Germany, 1978.

9. Mauer L. An interative track/train dynamic model for calculation of track error growth. Vehicle Syst Dynam 1995; 24(Suppl.): 209-221.

10. Guérin N. Approche expérimental et numérique du comportement du ballast des voices ferrées. $\mathrm{PhD}$ Thesis, Ecole Nationale des Pont et Chaussées, Paris, 1996.

11. Bordin V. Comportement du ballast des voices fereés soumises a un chargement vertical et latéral. PhD Thesis, Ecole Nationale des Ponts et Chaussées, Paris, 2001.

12. Al-Shaer A, Duhamel D, Sab K, et al. Experimental settlement and dynamic behavior of a portion of ballasted railway track under high speed trains. $J$ Sound Vibr 2008; 316: 211-233.

13. Ishida M, Namura A and Suzuki T. Track dynamic analysis for track settlement and irregularity growth. In Proceedings of Railway Engineering 2002, London, 2002.

14. Suiker A and de Borst R. A numerical model for the ciclic deterioration of railway tracks. Int $J$ Numer Meth Eng 2003; 57: 441-470.

15. Niemunis $A$, Wichtmann $T$ and Triantafyllidis $T$. A high-cycle accumulation model for sand. Comput Geotech 2005; 32(4): 245-263.

16. Wichtmann T. Explicit accumulation model for noncohesive soils under cyclic loading. PhD Thesis, Ruhr University of Bochum, Bochum, Germany, 2005.

17. Sawicki A and Swidzinski W. Mechanics of a sandy subsoil subjected to cyclic loadings. Int J Numer Anal Meth Geomech 1989; 13: 511-529.

18. Triantafyllidis $\mathrm{T}$, Wichtmann $\mathrm{T}$ and Niemunis A. Explicit accumulation model for granular materials under multiaxial cyclic loading. In: Proceedings of 6th international workshop on mathematical methods in scattering theory and biomedical engineering, Ioannina, Greece, 2003, pp.1-12.

19. Niemunis A, Wichtmann T and Triantafyllidis T. Explicit accumulation model for cyclic loading. In: International conference on cyclic behaviour of soils and liquefaction phenomena, Bochum, Germany, 2004, pp.65-76.

20. Wichtmann T, Niemunis A and Triantafyllidis T. Strain accumulation in sand due to cyclic loading: drained triaxial tests. Soil Dynam Earthquake Eng 2005; 25(12): 967-979.

21. Wichtmann T, Niemunis A and Triantafyllidis T. On the influence of the polarization and the shape of the strain loop on strain accumulation in sand under high-cyclic loading. Soil Dynam Earthquake Eng 2007; 27(1): 14-28.

22. Gudehus G. A comprehensive constitutive equation for granular materials. Soils Found 1996; 36(1): 1-12. 
23. Von Wolffersdorff PA. A hypoplastic relation for granular materials with a predefined limit state surface. Mech Cohesive-Frictional Mater 1996; 1: 251-271.

24. Niemunis A and Herle I. Hypoplastic model for cohesionless soils with elastic strain range. Mech CohesiveFrictional Mater 1997; 2: 279-299.

25. SIMULIA. Abaqus Analysis User's Manual, v6.11. Dassalt Systemes SIMULIA Corp., 2011.

26. Fellin W and Ostermann A. Consistent tangent operators for constitutive rate equations. Int J Numer Anal Meth Geomech 2002; 26(12): 1213-1233.

27. Bogacki P and Shampine L. A 3(2) pair of RungeKutta formulas. Appl Math Lett 1989; 2(4): 321-325.

28. Hairer E and Wanner G. Solving Ordinary Differential Equations II: Stiff and Differential-Algebraic Problems. New York: Springer, 2010.

29. Sloan SW. Substepping schemes for the numerical integration of elastoplastic stress-strain relations. Int $J$ Numer Meth Eng 1987; 24(5): 893-911.

30. Kuo CM and Huang $\mathrm{CH}$. Two approaches of finiteelement modeling of ballasted. $J$ Geotech Geoenviron Eng 2009; 135(3): 455-458.

31. Nguyen K, Goicolea J and Galbadon F. Comparison of dynamic effects of high-speed traffic load on ballasted track using a simplified two-dimensional and full threedimensional model. Proc IMechE Part F 2014; 2: 128-142.

32. Johnson K. Contact Mechanics. Cambridge: Cambridge University Press, 1985.

33. Hilber HM, Hughes TJ and Taylor RL. Improved numerical dissipation for time integration algorithms in structural dynamics. Earthquake Eng Struct Dynam 1977; 5: 283-292.

34. EN13848-5:2008. Railway Applications-Track-Track Geometry Quality Part 5: Geometric Quality Levels. European Committee for Standardization-European Union, rue de Stassart, 36B-1050 Brussels, 2008.

35. Esveld C. Modern Railway Track, 2nd edn. MRT Productions, 2001.

36. Bauer E. Calibration of a comprehensive hypoplastic model for granular materials. Soils Found 1996; 36(1): $13-26$.

\section{Appendix}

\section{A Constitutive functions of the Bochum accumulation model}

Using the hypoplastic flow rule, the direction of accumulation $\mathbf{m}$ in (2) can be approximated as

$$
m_{i j}=\frac{M_{i j}}{\|\mathbf{M}\|}
$$

where $\|\mathbf{M}\|=\sqrt{\operatorname{tr}\left(\mathbf{M}^{2}\right)}$ represents the Euclidean norm and

$$
M_{i j}=-\left[\left(\frac{F}{a}\right)^{2}\left(\hat{\sigma}_{i j}+\hat{s}_{i j}\right)+(\hat{\sigma}: \hat{\sigma}) \hat{s}_{i j}-\hat{\sigma}_{i j}(\hat{\sigma}: \hat{1} s)\right]
$$

with $\hat{\sigma}_{i j}$ the normalised stress tensor, $\hat{s}_{i j}$ ) the first invariant of $\sigma_{i j}$, defined in (34). The parameters $a$ and $F$ are defined in (35) and (36), respectively.
The six functions in (2) and the material constants corresponding to each function are summarised in Table A1.

In the expression of these function, the strain amplitude $\varepsilon^{\mathrm{ampl}}$ is determined through the recorded strain path, $p^{a v}$ is the average effective mean stress, $e$ is the void ratio, $N$ is the number of loading cycles, and the factor $\bar{Y}^{a v}$ is given by

$$
\bar{Y}^{a v}=\frac{Y-9}{Y_{c}-9}
$$

with

$$
Y=-\frac{I_{1} I_{2}}{I_{3}} \text { and } Y_{c}=\frac{9-\sin ^{2} \varphi_{c}}{1-\sin ^{2} \varphi_{c}}
$$

being $I_{1}, I_{2}, I_{3}$ the scalar invariants of the normalised average stress tensor $\hat{\sigma}_{i j}^{a v}$.

Table A2 presents the ballast material parameters for the accumulation model used in the numerical simulation in this paper.

\section{B Constitutive functions of the hypoplastcity model}

The tensor $\mathcal{L}$ and $\mathbf{N}$ in (3) are written as

$$
\mathcal{L}_{i j k l}=\frac{f_{b} f_{e}}{\operatorname{tr}\left(\hat{\sigma}^{2}\right)}\left(F^{2} \delta_{i k} \delta_{j l}+a^{2} \hat{\sigma}_{i j} \hat{\sigma}_{k l}\right)
$$

Table AI. Summary of the functions and material constant.

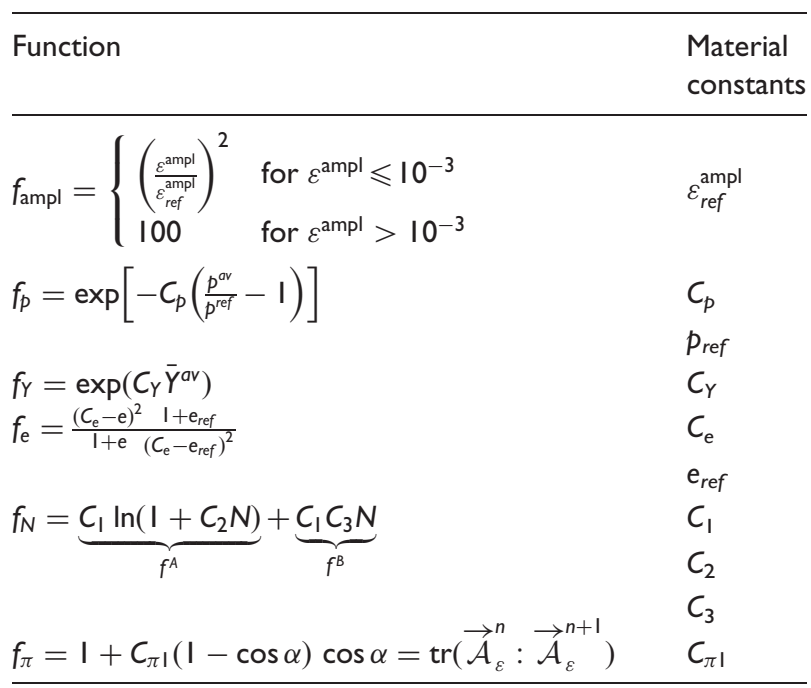

Table A2. Accumulation model parameters for ballast material.

\begin{tabular}{lllll}
\hline$\varepsilon_{\text {ref }}^{\text {amp }}$ & $C_{1}$ & $C_{2}$ & $C_{3}$ & $C_{p}$ \\
\hline$[-]$ & {$[-]$} & {$[-]$} & {$[-]$} & {$[-]$} \\
$10^{-4}$ & $5.7172 \times 10^{-4}$ & 1.6148 & $1.6987 \cdot 10^{-6}$ & 0.43 \\
$P_{\text {ref }}$ & $C_{Y}$ & $C_{e}$ & $e_{\text {ref }}$ & $C_{\pi 1}$ \\
{$[\mathrm{kPa}]$} & {$[-]$} & {$[-]$} & {$[-]$} & {$[-]$} \\
100 & 2.0 & 0.58 & 1.00 & 0.0 \\
\hline
\end{tabular}




$$
N_{i j}=\frac{f_{b} f_{d} f_{e} F a}{\operatorname{tr}\left(\hat{\sigma}^{2}\right)}\left(\hat{\sigma}_{i j}+\hat{s}_{i j}\right)
$$

where $\delta_{i j}$ is the Kronecker delta, and

$$
\hat{\sigma}_{i j}=\frac{\sigma_{i j}}{\operatorname{tr} \boldsymbol{\sigma}}, \quad \hat{s}_{i j}=\hat{\sigma}_{i j}-\frac{1}{3} \operatorname{tr}(\hat{\sigma}) \delta_{i j}
$$

The factors $a$ and $F$ are determined by the following formulations:

$$
\begin{aligned}
& a=\frac{\sqrt{3}\left(3-\sin \varphi_{c}\right)}{2 \sqrt{2} \sin \varphi_{c}} \\
& F=\sqrt{\frac{1}{8} \tan ^{2} \psi+\frac{2-\tan ^{2} \psi}{2+\sqrt{2} \tan \psi \cos 3 \theta}}-\frac{1}{2 \sqrt{2}} \tan
\end{aligned}
$$

being

$$
\tan \psi=\sqrt{3}|| \widehat{\mathbf{s}}||, \quad \cos 3 \theta=-\sqrt{6} \frac{\operatorname{tr}\left(\widehat{\mathbf{s}}^{3}\right)}{[\widehat{\mathbf{s}}: \widehat{\mathbf{s}}]^{3 / 2}}
$$

Three characteristic void ratios, the minimal possible void ratio $\left(e_{d}\right)$, the critical void ratio $\left(e_{c}\right)$ and the void ratio in the loosest state $\left(e_{i}\right)$, are dependent on the pressure in a relation proposed by Bauer: ${ }^{36}$

$$
\frac{e_{i}}{e_{i 0}}=\frac{e_{c}}{e_{c 0}}=\frac{e_{d}}{e_{d 0}}=\exp \left[-\left(\frac{3 p}{h_{s}}\right)^{n}\right]
$$

with the respective reference values $e_{i 0}, e_{c 0}, e_{d 0}$ for zero pressure. The constants $e_{i 0}, e_{c 0}, e_{d 0}$ with the $h_{s}, n$ are material parameters.

The scalar factor $f_{b}, f_{e}, f_{d}$ take into account the influence of mean pressure and density:

$$
\begin{aligned}
f_{d}= & \left(\frac{e-e_{d}}{e_{c}-e_{d}}\right)^{\alpha} \\
f_{e}= & \left(\frac{e_{c}}{e}\right)^{\beta} \\
f_{b}= & \frac{h_{s}}{n}\left(\frac{1+e_{i}}{e_{i}}\right)\left(\frac{e_{i 0}}{e_{c 0}}\right)^{\beta}\left(\frac{3 p}{h_{s}}\right)^{1-n} \\
& \times\left[3+a^{2}-a \sqrt{3}\left(\frac{e_{i 0}-e_{d 0}}{e_{c 0}-e_{d 0}}\right)^{\alpha}\right]^{-1}
\end{aligned}
$$

with $\beta$ the other material parameter.

The tensor $\mathcal{M}_{i j k l}$ in (5) has the form

$$
\begin{aligned}
\mathcal{M}= & {\left[\rho^{x} m_{T}+\left(1-\rho^{x}\right) m_{R}\right] \mathcal{L} } \\
& + \begin{cases}\rho^{x}\left(1-m_{T}\right) \mathcal{L}: \hat{\delta} \otimes \hat{\delta}+\rho^{x} \mathbf{N} \otimes \hat{\delta} & \text { if } \hat{\delta}: \mathbf{D}>0 \\
\rho^{x}\left(m_{R}-m_{T}\right) \mathcal{L}: \hat{\delta} \otimes \hat{\delta} & \text { if } \hat{\delta}: \mathbf{D} \leqslant 0\end{cases}
\end{aligned}
$$

Table BI. Hypoplastic material parameters.

\begin{tabular}{lllllll}
\hline$\left.\phi_{c}{ }^{0}\right]$ & $h_{s}[\mathrm{MPa}]$ & $n$ & $\mathrm{e}_{d 0}$ & $\mathrm{e}_{c 0}$ & $\mathrm{e}_{i 0}$ & $\alpha$ \\
\hline 33 & $\mathrm{I} 50$ & 0.40 & 0.65 & 1.00 & $\mathrm{I} .15$ & 0.05 \\
$\beta$ & $R$ & $m_{r}$ & $m_{T}$ & $\beta_{r}$ & $\chi$ & \\
4.0 & $4.5 \times 10^{-4}$ & 5.0 & 5.0 & 0.15 & 2.5 & \\
\hline
\end{tabular}

where $\rho=(\|\boldsymbol{\delta}\| / R), R, m_{R}, m_{T}, \chi$ are material parameters, $\|\boldsymbol{\delta}\|$ is the Euclidean norm of intergranular strain tensor. The direction of intergranular strain $\hat{\delta}$ is defined as

$$
\hat{\delta}= \begin{cases}\boldsymbol{\delta} /\|\boldsymbol{\delta}\| & \text { if } \boldsymbol{\delta} \neq 0 \\ 0 & \text { if } \boldsymbol{\delta}=0\end{cases}
$$

The intergranular strain tensor is determined by its evolution equation:

$$
\stackrel{\circ}{\boldsymbol{\delta}}= \begin{cases}\left(\square-\hat{\delta} \otimes \hat{\delta} \rho^{\beta r}\right): \mathbf{D} & \text { if } \hat{\delta}: \mathbf{D}>0 \\ \mathbf{D} & \text { if } \hat{\delta}: \mathbf{D} \leqslant 0\end{cases}
$$

with a parameter $\beta_{R}$. Here $\rrbracket$ is the unit tensor of fourth order $\left(I_{i j k l}=\delta_{i k} \delta_{j l}\right)$.

The material parameters used in the numerical simulation in this paper are given in Table B1.

\section{UMAT interface in Abaqus}

To introduce the user material into the input data file, the keyword $*$ USER MATERIAL is used. ${ }^{25}$ The following input lines should be included to specify the user material:

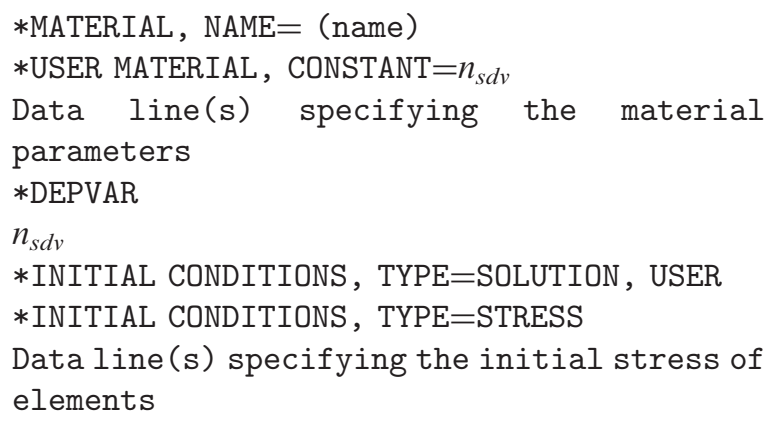

Herein, the $*$ MATERIAL keyword specifies the name of the user material. As a crucial point, the *USER MATERIAL keyword is required to specify material parameters for the UMAT. The $*$ DEPVAR is needed when the material model contains internal variables state and is necessary for the allocation of space for $n_{s d v}$ variables state at each integration point. The *INITIAL CONDITIONS, TYPE=SOLUTION, USER option is used to initialise non-zero internal variables state via user subroutine SDVINI. ${ }^{25}$ The *INITIAL CONDITIONS, TYPE=STRESS specifies the initial stress in the elements. 